\title{
Appraisal of the requirements for establishing domestic roof rainwater harvesting schemes in Bangladesh
}

Received (in revised form): 8th May, 2008

\section{David R. Moore}

is a reader at the Scott Sutherland School of Architecture \& Built Environment, Robert Gordon University. His research activities range from buildability through sustainable design, to perception and cognition in a construction industry context. He has been involved in funded research rated as tending to international significance by EPSRC. He has authored books covering various aspects of project management, one of which (Project Management - Designing Effective Organisational Structures in Construction) has been recently published in simplified character Chinese. Dr Moore is a professional member of the Chartered Institute of Building (MCIOB) and the Association of Researchers in Construction Management.

\section{Simon N. Mclean}

is a chartered building surveyor and academic. He leads the Building Surveying programme at Nottingham Trent University, and lectures in practical Building Surveying. Simon has been involved from a practical perspective in alleviating poverty and the effects of natural disasters in Bangladesh through the introduction of sustainable technologies for improving the durability of vernacular construction materials for a number of years, and has co-authored a number of academic papers, as well as being involved in funded research in to provision of such sustainable technologies.

Correspondence: David R. Moore, The Scott Sutherland School of Architecture and Built Environment, The Robert Gordon University, Garthdee Road, Aberdeen, AB10 7QB, UK; Tel: + 44 (0)1224 263719; Fax: +44 (0)1224 263777; E-mail: d.m.moore@rgu.ac.uk

\begin{abstract}
Bangladesh is one of the world's poorest countries, and additionally suffers frequent natural and humanitarian disasters, such as loss of shelter following cyclones, flooding and arsenic poisoning of well water supplies. One possible solution is the regionally sustainable production of durable building materials, which would resist the actions of flooding and provide a roof surface suitable for the harvesting of rainfall, to provide a source of clean drinking water. Current vernacular shelters have however evolved to suit the social needs of the indigenous people and the materials used in their construction are mostly harvested locally. This paper evaluates the requirements for successful harvesting of rainwater and how such requirements might be sustainably achieved in the context of rural and peri-urban Bangladesh.

Journal of Building Appraisal (2008) 4, 23-31. doi:10.1057/jba.2008.13
\end{abstract}

\section{Keywords:}

rainwater harvesting, vernacular construction form, sustainable building material production, potability

\section{INTRODUCTION}

This paper focuses on the suitability of the construction form of vernacular shelters in Bangladesh for the implementation of Domestic Scale Rainwater Harvesting schemes, (DRWH), in response to the problems of unsafe water in Bangladesh, a country that is in the unenviable situation of suffering from a frequent excess of water, in terms of severe flooding of large areas of its predominantly flat terrain. It does however also suffer from severe problems concerning the quality of the water available for human consumption. 
A recent addition to the problem of water quality in connection with cholera, etc is the discovery of arsenic levels in tube-well water 70 times higher than the safe limit set by Bangladesh's national water drinking standards of $0.05 \mathrm{mg} / \mathrm{l}$ (WHO, 2002a). It is worth noting that these standards are themselves a factor of five higher than the global standards suggested by WHO at $0.01 \mathrm{mg} / \mathrm{l}$ (WHO, 2002b). The emergence of arsenecosis is in addition to the 'traditional' problem of the availability of clean water generally, which is illustrated by two examples from the slums of Bangladesh's capital, Dhaka. Vidal (2002) discusses the nature of the clean water problem in the slums of Balurmath and Outfall. Balurmath is near the centre of Dhaka, and around 5,000 people are squeezed onto a few acres of land with no water supply, health services or drainage beyond a large ditch full of waste. The nearest water supply is about a 20 minute walk away, and it is usual for individuals to spend several hours each day collecting water, a situation that may be more readily anticipated in rural rather than urban areas. In addition to the working hours lost through illness and loss of capability due to arsenecosis and other water-borne diseases, it is not unusual for women in rural Bangladesh to travel large distances to source suitable water (Smet and Moriarty, 2001). As women have a strong part to play in the agricultural process (in rural areas, but also in other forms of economic activity in urban areas) this lost labour capacity must be factored in to the family economics when assessing the value of doorstep drinking water. Another factor for consideration is the losses in educational opportunity as young girls carry water rather than attend school.

\section{ARSENIC POISONING IN BANGLADESH}

The primary water-related poison in Bangladesh is arsenic that, while not unique to Bangladesh (USA, Mexico, Chile, India, Argentina, China and Thailand also suffer from high arsenic levels in drinking water (WHO, 2002c)), does affect the country particularly severely. Cited estimates of Bangladeshis potentially affected by arsenic poisoning range from 65 million across 52 of the country's 64 districts in 1998 (Islam, 1998) to 90 million across 59 districts in 2000 (Islam, 2000). These figures evidence an escalating problem, if only for the fact that arsenecosis can take-up to 14 years to manifest itself (Islam, 1998) and therefore further cases can realistically be expected to emerge for several years even if the source problem can be immediately resolved. The nature of the arsenic problem is essentially a geological one. Silt brought over the centuries from the Himalayan Mountains by annual floodwaters enriches the fertility of the soil (ISDWC, 2002). It is also believed that these silts can contain varying levels of arsenic, and that this permeates into, and then contaminates, water aquifers. It has been proposed that the desorption of arsenic in these sedimentary soils has been accelerated through renewal of shallow aquifer waters due to an increase in the use of tube-wells for providing drinking and irrigation water (Aggarwal et al., 2000). Concentrations of arsenic in two thirds of 8,000 tube-wells tested in Bangladesh are in excess of the national drinking water standards maximum level of $0.05 \mathrm{mg} / \mathrm{l}$ (Islam, 1998). Ironically, tube-wells were introduced to combat groundwater pollution by taking drinking water from deeper, and thereby cleaner, aquifers. Contaminated tube-wells are now being painted red under a United Nations development initiative to warn villagers not to use them. This leaves the people affected once again largely dependent upon low quality ground water.

The human aspect of arsenic poisoning is manifest physically in terms of damage to the immune system, fatigue, vomiting and diarrhoea. Further symptoms include melanosis (abnormal black-brown pigmentation of the skin), hyperkeratosis (thickening, in extreme cases resulting in a covering of black, bulbous swellings) of the palms and soles, gangrene of the lower limbs and skin cancer (WHO, 2002a). Such can be the appearance of those 
suffering from advanced arsenocosis that they have been treated in a manner similar to lepers, being socially ostracised and thus making it difficult for them to provide for themselves. There have been cases of female arsenocosis sufferers being deserted or divorced by their husbands (SOES, 1997). Symptoms appear to be alleviated by a diet of fresh vegetables, fruits and high protein foods, which are the very foods typically unavailable to those in poverty (Islam, 1998). Along with alleviation, there is a need for prevention. One possible means of supplying water that is both arsenic and water-borne disease free is through rainwater harvesting $(\mathrm{RWH})$. The general principle is to collect rainwater as it runs off the roofs of buildings or other surfaces, into storage tanks. A number of different types of RWH schemes have been tried throughout the developing world, with the effectiveness of the process depending upon a number of factors; one significant factor being the form of construction for the surface used to collect the rainwater.

\section{TYPICAL SHELTER FORM IN RURAL AND PERI-URBAN REGIONS OF BANGLADESH}

A typical rural Bangladeshi house would be a small single-celled structure, mainly constructed of locally available materials such as earth, bamboo, reed and palm leaf (Muktadir and Hassan, 1985). Building commences on a plinth of rammed earth. The earth block or woven panel walls are fixed to the plinth using bamboo poles or timber. A palm leaf (or Golpata) thatch on a bamboo frame achieves reasonable resistance to the ingress of rain, but has a short life span. The porous walls are protected from downpours by the overhang of the roof. Typically, there is no formal drainage, only the capability of the roof to shed water away from the base of the structure.

Much of the housing in rural Bangladesh is essentially temporary due to the inability of the materials used to withstand damage by floodwater. These materials are, however, indigenous, inexpensive and perceived to be in abundant supply. The perception of abundant supply is, however, starting to become erroneous. This is evidenced by a recently commissioned report claiming that stocks of some species of Bamboo and Rattan have almost disappeared through over-harvesting and land clearance (Nuruzzaman, 2004). The transient nature of the houses acts as a disincentive to supplying fixed services to improve their basic amenities. This is evidenced by the fact that 70 per cent of Bangladeshi families do not have access to an electricity supply (Ahsan, 2004).

Houses in Bangladesh have evolved to suit popular culture, both social and religious. The implementation of different architectural practices (such as Western style housing) has not been successful in rural Bangladesh (Muktadir and Hassan, 1985). A more realistic approach would look to improved vernacular materials that provide better moisture resistance and greater durability and could provide of shelters capable of withstanding flooding. This will, in turn, reduce the reconstruction cost demand.

\section{THE TECHNOLOGY OF DRWH IN BANGLADESH}

Domestic scale RWH (DRWH) is a variation that has been piloted in several areas of Bangladesh. An important body in financing such schemes is the World Bank, which has allocated $\$ 32.4 \mathrm{~m}$ of credit for tackling arsenic contamination in Bangladesh. This forms part of a $\$ 44.4 \mathrm{~m}$ initiative administered by the International Development Agency (World Bank, 2002). In order to commence harvesting rainwater from domestic rooftops, all that is required is a suitably covered roof, some form of conduit (usually guttering) and a storage vessel. The first two of these have traditionally been regarded as relatively straightforward to achieve (nonetheless, this paper will present suggestions for 
improvements with regard to construction of a collecting surface), and so technological advances regarding RWH schemes have been sought in achieving effective storage facilities. Cost implications have been the primary consideration within this focus, and various designs of storage tank, utilising a range of different materials (butyl rubber, concrete jars and low cost horizontal water bags comprising a double skinned plastic bag supported inside a steel tube), have been tested (Nunley, 2001). The water bag method needs the base of the bag to be set in brick or concrete to avoid mosquitoes laying eggs in the water. The concrete jars are produced regionally from moulded concrete reinforced by bamboo. They are set upon plinths constructed from local waste materials and constructed partly by local labour. The comparison between these two methods of storage is useful in that costs are comparable at around $\$ 35$ for manufacture and installation of a facility to supply an average sized family during the five-month dry season. Water bags, however, require materials to be brought in to the region, whereas concrete jars could, in many regions, utilise local materials.

Several problems have been identified in association with setting up DRWH schemes in Bangladesh. The traditional thatched roof of urban and, to a lesser extent, peri-urban areas, for example, is an unsuitable form of construction for RWH. An alternative material is profiled steel sheeting, which is an ideal material for collecting water, but lacks durability due to corrosion and has a low resistance to cyclonic and flood damage (Weiler, 1998). Also, it does not provide good thermal resistance (Muktadir and Hassan, 1985). Reference to CIBSE tables for thermal conduction of building materials shows that steel is not a good insulator, making dwellings unduly hot during sunlight hours (Weiler, 1998). A further problem is that the sheeting is an industrial product and not produced in rural Bangladesh, thereby requiring being imported, resulting in an outflow of wealth. This problem also applies to steel and plastic guttering and pre-fabricated storage tanks. Using nonvernacular materials results in a need to import further resources, as and when units need maintenance and replacement. Not only does this contribute to an outflow of wealth, but it also, due to inadequacies in transport infrastructure (ADB, 1999), could affect serviceability and the ability to store water for the dry season.

Bodies such as the International Development Agency have sought to identify and communicate the economic and environmental benefits of using vernacular materials for storage tank manufacture. There are, however, problems to be addressed within such a strategy, as evidenced by attempts to use local bamboo instead of processed materials for guttering and down pipes. These vernacular gutters were less efficient than engineered guttering capable of catching 90 per cent of the water flowing from a roof and costing under $\$ 4.50$ per $10 \mathrm{~m}$ run (Martinson et al., 2002). Materials suitable for guttering materials include UPVC, bamboo, steel and ceramic, or any material that maintains dimensional stability and resists moisture penetration. Finally, adequate gutter sizing is essential to avoid water losses, particularly during monsoon storms (Smet and Moriarty, 2001). Achieving roofing materials that perform effectively in the context of the climatic conditions in Bangladesh has not thus far been adequately addressed during DRWH development programmes.

The water, once gathered, is sent via guttering and pipes to the storage tank. It is usual to run the water through a filter before storage. This can, however, be a simple woven cotton filter, with sari material (when folded at least four times) having proved to be surprisingly effective in reducing new cholera cases by about 50 per cent of the historic average (BBC, 2003a). Storage is undertaken in either an above or below ground storage tank. The usual materials for tanks are butyl rubber, UPVC, metal, GRP, brick, concrete and timber, with materials tending to be those available locally. It is important to note that 
the use of underground tanks in areas of high rainfall and polluted groundwater can lead to polluted water entering the tanks. Additionally, underground tanks with low volumes of water at the end of a dry season can be made to float by heavy ground water levels (Smet and Moriarty, 2001). Underground tanks are therefore suggested as not being generally applicable in the Bangladesh environment.

Looking at the collection process, required roof areas and tank volumes depend upon water usage. An estimated tank size to provide a RWH contribution to an annual water demand for a family of six $\left(22 \mathrm{~m}^{3}\right.$ of drinking water) in a location producing $700 \mathrm{~mm}$ of rainwater during a three-month wet period is $17 \mathrm{~m}^{3}$. To achieve this a tank of $1.5 \mathrm{~m}$ radius and $1 \mathrm{~m}$ depth would need to be linked to a catchment roof of $40 \mathrm{~m}^{2}$ with a gathering efficiency of 80 per cent (ibid.). The cost of the storage tank is significant in a DRWH scheme; an example being a $4.3 \mathrm{~m}^{3}$ plastic tank, costing \$126 dollars in Kenya in 1998 (Smet and Moriarty, 2001). The estimated cost of rainwater harvesting is typically cited as being between US\$20-30 dollars per capita, which in a country such as Bangladesh may seem prohibitive when compared to the typical US\$16-20 for underground welling. Four further considerations, however, require to be factored into the comparison of value. First, costs can be reduced by up to 50 per cent through use of vernacular materials such as wattle and daub tanks with a polythene liner (Thomas and Martinson, 2002). Secondly, costs can be reduced through prudent water management, allowing smaller tanks to meet more clearly controlled uses. Thirdly, savings can be achieved through communal storage schemes that benefit from economies of scale, with a cost to size ratio of 0.65 being cited (ibid.). In principle, tank and catchment area sizes depend upon the maximum expected period with no rainfall. Finally, in Bangladesh, where the aquifers are often contaminated with arsenic, it can be argued that there is simply no ethical scope for such cost comparison exercises.

A further issue applicable to all DRWH schemes is that of water quality and the potential need to deal with chemical and biological contaminants. While not as pure as it may be believed to be, due to the fact that rainwater will dissolve airborne contaminants, no evidence has been found by the authors to define rainwater in rural Bangladesh as being generally unfit to drink, unlike ground and deep aquifer water. There will doubtless prove to be local exceptions to this potability heuristic (large industrial areas may well have particular micro-climate issues), and any actual need for filtration and disinfecting procedures would depend upon the local contaminants identified. Provided the water is filtered, stored hygienically and kept separate from biological contaminants, its use should reduce the risks of water-borne diseases such as cholera, which are present in groundwater (Thomas and Martinson, 2002). Acknowledgement of the difficulty of keeping stored drinking water contaminant free allows for the inclusion of 'cleaning' strategies such as the use of solar disinfection to deal with water-borne bacterial contamination. Solar disinfection is, however, not without its problems, four of which are:

- Can take up to two consecutive days under 100 per cent cloudy sky, with a minimum of five hours under bright or up to 50 per cent cloudy sky (BBC, 2003b).

- Will not work on water having turbidity levels higher than 30 NTU (SODIS, 2002).

- SODIS bottles should be filled completely as air interfaces reduce the intensity of UV-A radiation (SODIS, 2002).

- Concerns over the pollution impact of the required plastic (PET) bottles (BBC, 2003b).

The first two problems may be mitigated through the use of solar disinfection in conjunction with solar kiln technology. Through the ability of the kiln's reflector to 
collect and focus solar radiation, greater levels of UV-A radiation can be brought to bear on the water container, thus it is possible that both the 'processing' time and the ability to penetrate through high turbidity levels may be enhanced. Given the proposed nature of solar kiln usage, the completion of solar disinfection would represent a peripheral, but potentially significant (through decreased levels of illness) adjunct. It is also possible that, in Bangladesh and other similar countries, safe drinking water could have a commercial, as well as health, value with respect to issues such as the number of hours spent collecting water from distant sources. Any commercial value of surplus water could be a factor to offset against higher costs attributable to provision of larger storage facilities. This is important as additional income from selling water ranked alongside having water ready for use, and ahead of having clean water in a survey of perceived user benefits of DRWH (DTU, 2002). A particular feature of Bangladesh is that even distant water sources may not be available in the future as tube-wells close due to high levels of arsenic.

\section{ATTITUDES AND POLICIES REGARDING DRWH}

Governmental policies and international attitudes to rainwater harvesting are not always strongly defined. An investigation of three developing countries where DRWH has been implemented found no explicit reference to it in any national policy document, despite many mentions of failures in supplies of rural drinking water supplies. The countries involved were Ethiopia, Uganda and Sri Lanka. This lack of policy has been detrimental to the development of DRWH in Ethiopia and Uganda, but not in Sri Lanka, where donor supported projects have continued without a clear governmental policy. In Bangladesh, however, there is a written policy document and a five-year plan with regard to provision of drinking water. Unfortunately, neither the policy document nor the five-year plan promises firm action to tackle the current arsenic poisoning problem, and tube-wells are still being cited as the main vehicle for supply of drinking water, other than a brief mention in the five-year plan of the need to gather rainwater (GPRB, 1998). There is also a central theme of self-help and self-finance. The National Water Policy talks of stakeholder participation, while the five-year plan notes the problem of rural users bearing the costs of water and sanitation facilities. This economic theme recurs widely, as water is increasingly seen as a commercial resource (Chadwick and Datta, 2001). In providing drinking water to rural Bangladesh, RWH schemes fall into stated national policies for the provision of drinking water. The nature of such schemes as potential self-help initiatives would make them more viable as a solution to the current contamination problem than waiting for governmental intervention. The possibility of trading surplus clean water to generate primary wealth means that such schemes may tackle poverty alleviation on more than one front through the selling of any surpluses of both solar disinfected water and solar manufactured building materials.

A further consideration with regard to DRWH schemes, in addition to any national policies and attitudes to DRWH, is the attitude of the potential users. A global survey of attitudes was commissioned to supply information to bodies involved in supplying aid for water supplies. These include the World Bank, UNICEF, Christian Aid, Oxfam and Aid America. The survey found greatest levels of interest among females (ERB, 1998). This is not surprising as the task of carrying water home from remote sources usually falls to women (Smet and Moriarty, 2001). The survey also found a problem in some arid areas of the processing (particularly what was regarded as 'making' water) of rainwater being viewed as pagan practice, and thus unacceptable. This, however, should not be material in Bangladeshi culture, which revolves around the coming of the monsoon. General conceptions are that rainwater is pure, a situation that may not prove to be true in polluted 
atmospheres (DTU, 2002). Attitudes to rainwater differ across the globe and a survey of acceptability of rainwater for drinking ranged from 94 per cent in Uganda to 35 per cent in Ethiopia (ibid.). Given that there appears to be no significant cultural problem regarding the acceptance of rainwater for drinking, the technical problems of providing a DRWH system applicable in the context of Bangladesh, and the ethical problems of providing the system in the context of sustainable aid, can be addressed.

\section{TILED ROOFS FOR PROVISION OF DRWH}

This is an area apparently neglected in development research for DRWH. In a comprehensive report on producing low-cost systems in developing countries, all the issues mentioned thus far were included, but the provision of roofs suitable for DRWH was not. The fact that vernacular thatched roofs were unsuitable was seen as a limiting factor, but no work on producing suitable surfaces was considered (DTU, 2002). This may have been due to perceptions of cost arising from consideration of an 'automatic' alternative such as corrugated steel sheet. If the cost of providing DRWH suitable roofing was offset against the need to provide more durable shelters capable of greater resistance to flood damage, then a more equitable perspective of value can be established, allowing for a more creative approach to dealing with ground water and deep aquifer water pollution, and the fact that thatch is unsuitable for DRWH, such as the provision of replacement roofs as part of DRWH projects.

The technical criteria for providing suitable rainwater harvesting roofing surfaces can be readily established in terms of the surface's durability, permeability, etc. The roof surface must be durable in order to give economic service, resist high levels of moisture and high winds. Installation of the roof must not seriously detract from the thermal performance afforded by the vernacular thatched roof. There is, however, also the issue of funding for such schemes. If initially funded by aid, the materials need to be produced regionally, thus engaging the recipients and in a manner that will allow the phased withdrawal of external aid as the local population incrementally engage in wealth generation. Two tried and tested roof materials are corrugated steel sheets and clay tiles. Other options such as shingles and slates are not to be considered due to a lack of such raw materials in rural Bangladesh. Steel is simple to erect and maintain. Its durability due to corrosion is limited, however, resulting in a source of lead contamination, as lead is an impurity in the galvanising process (DTU, 2002), and it does not perform well in high winds: a steel roof sheet propelled by high winds is a formidable weapon (Weiler, 1998). Steel is a conductor of heat, unlike clay and thatch, which are insulators, resulting in increased thermal gains to a house over traditional roofing materials. There is also the barrier of money: steel sheeting requires expensive production facilities and specific raw materials, both of which may have to be imported, resulting in an either outflow of wealth from the local population, or a constant inflow of aid subsidies. On the basis of providing a sustainable aid-based disaster relief strategy, steel sheeting is not appropriate to a DRWH scheme.

As part of a tile production strategy, a number of design issues become important. If the tiles are to be made locally then their design must meet requirements for such production. Tiles can be produced in a variety of shapes, thus presenting opportunities to match with, or indeed create, a vernacular architecture. Flat shingle-like units, for example, need to be installed in a double-lap manner to avoid water ingress to the habitable space through joints. This increases the number of tiles used and increases the requirements for supporting rafters and purling. Interlocking tiles do not require the double lap, but their curved profile makes hand forming a more skilled process, and 
reduces the number that can be stacked into a kiln. A possible solution could be to adopt a long-proven technology. The Romans designed one of the earliest examples of tiled roofs in a simple single-lap construction called a Tegulas Roof. In this roof simple flat tiles called Tegulae were laid side by side. These evolved from timber shingles and differed only by means of a small edge lip. The joints were protected by the installation of longitudinal courses of Imbrices. These were semi-cylindrical tiles working in a similar manner to modern ridge tiles. Such a roof would be lighter than a double lapped alternative. It would require simply crafted components suitable for rural manufacture. There would be the required channels for directing harvested rainwater to a guttering system. The existence of surviving Roman Tegulae and Imbrice tiles bear testament to the durability of such units. A quote from Roman texts cited by William Smith stated, 'By the exact adaptation of the broad tegulae and the narrow Imbrices throughout the whole of its extent, became like one solid and compact framework' (Yates, 1895). These are qualities required of a structure designed to provide a durable roof in areas of extreme weather. The Tegulas example provides evidence that tiled roofs suitable for local conditions and for rainwater harvesting can be fabricated in rural areas using simply made components.

\section{CONCLUSIONS}

The extent of arsenic poisoning of drinking water in Bangladesh represents a problem that needs to be addressed, particularly when allied with the longer established problems of general drinking water quality, particularly with regard to water conveyed diseases such as cholera and malaria. The provision of clean and safe drinking water is thus an urgent requirement, and rainwater harvesting presents a possible means of meeting it. In order to achieve an efficient harvesting system, the dearth of durable forms of shelter needs to be addressed. More durable forms of shelter will provide suitable surfaces from which to collect rainwater and also reduce the problem of shelters being damaged through flooding.

The production of durable shelters requires the manufacture of impervious building materials, with clay or concrete tiles being one possibility. A strategy for their production, along with other required materials such as building lime, through the use of solar kiln technology is proposed. This strategy presents opportunities for other beneficial outcomes such as solar disinfection of harvested rainwater. The disinfected water, along with 'surplus' building materials, represents a commodity with a commercial value that could be realised and thus contribute to wealth generation.

\section{References}

Aggarwal, P.K., Basu, A.R., Kulkarni, K.M., Froelich, K., Ahmed, M.A.N. and Ahmed, S.R.H. (2000) Isotope Hydrology of Ground Water in Bangladesh: Implications for Characterization and Mitigation of Arsenic in Groundwater. IAEA — TC Project (BGD/8/016).

Ahsan, S. (2004) Harnessing Power from the Sun. Daily Star Cover Story 13th February, 2004, www.thedailystar.net/ magazine/2004/02/01/coverstory.htm.

Asian Development Bank (1999) Country Assistance Plan, www.bangladesh-review.co.uk.

BBC (2003a) Cloth Filter could cut Cholera Deaths, www.bbc.co.uk/2/hi/health/2640307.stm.

BBC (2003b) Pure Water Aid, www.bbc.co.uk/worldservice.sci_tech/highlights/010327_purewater.shtml.

Chadwick, M. and Datta, A. (2001) Livelihood-Policy Relationships in South-East Asia. Mathew Chadwick and Anjan Datta Livelihood-Policy Relationships in South-East Asia, Working Paper 1, www.geog.leeds.ac.uk.

Development Technology Unit (DTU) (2002) Very-Low-Cost Domestic Rainwater Harvesting in the Humid Tropics: Constraints \& Problems. DFID KaR Contract R7833 Report R2, January 2002, Warwick University.

ERB (1998) Domestic Rainwater Harvesting in the Humid Tropics. Project ERB IC18 CT98 0276 Attitudes Towards Rainwater Harvesting, Department of Engineering, Warwick University. 
GPRB (1998) National Policy for Safe Water Supply \& Sanitation 1998, Local Government Division, Ministry of IGRD and Co-operatives, Bangladesh.

International Secretariat of the Dialogue on Water and Climate (ISDWC) (2002) Coping with Water \& Climate in Bangladesh. Key Issues, June 2002, Bangladesh.

Islam, T. (1998) Health-Bangladesh: Clean Drinking Water Turns Poisonous. World News, Interpress Release, March 1998, Bangladesh.

Islam, T. (2000) Donors want Arsenic Pollution Curbed Faster. Asia Times 26th May, 2000, Bangladesh.

Martinson, D., Ranatunga, N. and Gunarane, A. (2002) Reducing Rainwater Harvesting System Costs. 28th WEDC Conference, Calcutta.

Muktadir, M. and Hassan, D. (1985) Traditional House Form in Rural Bangladesh. Conference Regionalism in Architecture Bangladesh. Archnet.org/library/document id2808.

Nunley, D. (2001) The Sky's the Limit: IDE Unveils Low-Cost Rainwater Harvesting Systems in Bangladesh. Issue Advisory Group on Fresh Water www.earthsumit2002.org.ic.

Nuruzzaman, M. (2004) National Report on the State of Bamboo and Rattan Development in Bangladesh, Government of The People's Republic of Bangladesh Forestry Department Report, Dhakar.

Smet, J. and Moriarty, P. (2001) Rooftop Rainwater Harvesting, International Water \& Sanitation Centre DGIS, Netherlands.

SODIS (2002) Abstract Topic 1 Technical Aspects. E-Conference on Solar Water Disinfection, SODIS. www.sodic.ch/ SODIS_e-conference.htm.

SOES (1997) Groundwater Arsenic Concentration of Lakshmipur District appears to be High, Unpublished SOES report, Jadavpur University, Calcutta, cited in WHO (2002a).

Thomas, T.H. and Martinson, D.B. (2002) Economically Viable Domestic Roofwater Harvesting. 28th LOEDC Conference, Kolkata, India.

Vidal, J. (2002) Filthy Water Poisons the People of Dhaka's Festering Slums. The Guardian, 23rd March, 2002. www.guardian.co.uk/debt/Story/0,2763,672685,00.html.

Weiler, K.H. (1998) One World Sun (OSOW) Project Introduction, Http://spot.fho-emden.de/hp/weiler/osow.html. WHO (2002a) Women's Health in South-East Asia, w3.whosea.org/women/ch5.htm.

WHO (2002b) Water Drinking Guidelines, w3.whosea.org.techinfo/water.htm.

WHO (2002c) Water, Sanitation and Hygiene Links to Health, www.who.int/inf-fs/en/fact210.html.

World Bank (2002) Bank Moves to Reduce Bangladesh Arsenic Poisoning, htttp://web.worldbank.org/WBSITE/ EXTERNAL/NEWS//0contentMDK:200119121.

Yates, J. (1895) Article on a Dictionary of Greek and Roman Antiquities, by William Smith, John Murray Publishing, London, pp. 1098-1099. 